\title{
Antihypertensive treatments in adult autosomal dominant polycystic kidney disease: network meta-analysis of the randomized controlled trials
}

\author{
Cheng Xue ${ }^{1,2, *}$, Chenchen Zhou ${ }^{1, *}$, Bing Dai ${ }^{1}$, Shengqiang $Y u^{1}$, Chenggang $X u^{1}$, \\ Zhiguo Mao ${ }^{1}$, Chaoyang Ye ${ }^{1}$, Dongping Chen ${ }^{1}$, Xuezhi Zhao ${ }^{1}$, Jun Wu ${ }^{1}$, Wansheng \\ Chen ${ }^{1,3}$ and Changlin Mei $^{1}$ \\ ${ }^{1}$ Department of Nephrology, Shanghai Changzheng Hospital, Second Military Medical University, Shanghai, China \\ 2 Department of Nephrology, PLA 309 Hospital, Beijing, China \\ ${ }^{3}$ Department of Pharmacy, Shanghai Changzheng Hospital, Second Military Medical University, Shanghai, China \\ * These authors have contributed equally to this work \\ Correspondence to: Changlin Mei, email: mc1312@126.com \\ Keywords: polycystic kidney disease, autosomal dominant, antihypertensive drug, glomerular filtration rate, urinary albumin excre- \\ tion, Pathology Section \\ Received: August 12, $2015 \quad$ Accepted: November 21, $2015 \quad$ Published: December 02, 2015
}

\section{ABSTRACT}

Background: Blood pressure (BP) control is one of the most important treatments of Autosomal dominant polycystic kidney disease (ADPKD). The comparative efficacy of antihypertensive treatments in ADPKD patients is inconclusive.

Methods: Network meta-analysis was used to evaluate randomized controlled trials (RCT) which investigated antihypertensive treatments in ADPKD. PubMed, Embase, Ovid, and Cochrane Collaboration were searched. The primary outcome was estimated glomerular filtration rate (eGFR). Secondary outcomes were serum creatinine (Scr), urinary albumin excretion (UAE), systolic BP (SBP), diastolic BP (DBP), mean artery pressure (MAP) and left ventricular mass index (LVMI).

Results: We included 10 RCTs with 1386 patients and six interventions: angiotensin-converting enzyme inhibitors (ACEI), Angiotensin II receptor blocker (ARB), combination of ACEI and ARB, calcium channel blockers (CCB), $\beta$-blockers and dilazep. There was no difference of eGFR in all the treatments in both network and direct comparisons. No significant differences of Scr, SBP, DBP, MAP, and LVMI were found in network comparisons. However, ACEI significantly reduced SBP, DBP, MAP and LVMI when compared to CCB. Significantly increased UAE was observed in CCB compared with ACEI or ARB. Bayesian probability analysis found ARB ranked first in the surrogate measures of eGFR, UAE and SBP.

Conclusions: There is little evidence to detect differences of antihypertensive treatments on kidney disease progression in ADPKD patients. More RCTs will be needed in the future. Use of ARB may be an optimal choice in clinical practice.

\section{INTRODUCTION}

Autosomal dominant polycystic kidney disease (ADPKD) is characterized by continuous enlargement of kidney cysts. ADPKD is the most common hereditary nephropathy with prevalence from $1 / 1000$ to $1 / 400$ [1]. ADPKD patients develop hypertension early, which increases the renal progression. ADPKD patients with hypertension have faster and greater annual rates of total kidney volume (TKV) growth, and an increased prevalence of cardiovascular complications when compared with the normotensive patients. Healthcare for ADPKD mainly focuses on hypertension to reduce mortality and morbidity. Currently, blood pressure (BP) control is one of the most important clinical treatments of ADPKD. 
The renin-angiotensin-aldosterone system (RAAS) plays an important role in hypertension pathogenesis in ADPKD [2]. RAAS inhibitors (RASI) include Angiotensin converting enzyme inhibitor (ACEI) and Angiotensin II receptor blocker (ARB). RASIs have been proved to slow renal progression in non-diabetes chronic kidney disease (CKD), and are widely used in clinical practice of ADPKD. Besides, calcium channel blockers (CCBs), $\beta$-blockers, dilazep and the diuretics also were used in ADPKD with hypertension [3-5]. There was no difference in renal function between ACEI and placebo [6]. Kanno et al. [7] found CCB showed higher creatinine clearance compared with ACEI. However, a randomized controlled trial (RCT) found renal function was similar between amlodipine and enalapril [8]. Recently, the Halt Progression of Polycystic Kidney Disease studies (HALTPKD) $[1,2]$ observed a negative effect of the combination of ACEI and ARB on renal function compared with ACEI monotherapy.

Each RCT just contained only two or three drugs. It is hard to get a head-to-head outcome comparing the drugs of interest or get all the drugs to integrate some specific effects together [9]. This study aimed to use network and traditional meta-analysis to assess the direct and indirect effects of antihypertensive treatments in ADPKD.

\section{RESULTS}

Ten RCTs with 1,386 participants were included after assessment of 45 full-text articles and 197 records [1-8,10-15]. Electronic searching process was shown in the flowchart (Figure 1). Eight trials were two-grouped, and two trials were four-grouped. The network of included treatment comparisons was shown in Figure 2. ACEIs were the most frequently studied agents. The baseline characteristics were summarized in Table 1. The mean follow-up time was about four years (range $0.5-8$ years). Male/female proportion was balanced in all trials. The hypertension criteria in the studies was $>140 / 90 \mathrm{~mm} \mathrm{Hg}$. Two studies $[6,15]$ divided patients into hypertension and normal BP groups.

The overall risk of bias of the included studies was shown in Figure 3. Random sequence generation was adequate in two studies. $60 \%$ studies did not present adequate blinding. Only three studies used intention-totreat analyses. Predefined endpoints were reported fully in four studies.

Network comparisons for primary outcome eGFR were shown in Table 2. There was no difference of eGFR in all the treatments (seven studies, five treatments, Supplemental Figure 1). There was no increased eGFR with ACEI, ARB, or ACEI+ARB when compared with $\beta$-blocker or CCB either in the consistency model or in the inconsistency model.

Table 3 showed network comparisons for the Scr. No significant difference was found in all the treatments (five studies, four treatments, Supplemental Figure 2). There was no decreased Scr with ACEI or ARB when compared with $\beta$-blocker or CCB either in the consistency model or in the inconsistency model. Table 4 showed the network comparisons for the UAE (seven studies, five treatments, Supplemental Figure 3). UAE in ACEI, ARB, ACEI+ARB and $\beta$-blocker did not differ, but UAE tended to be higher in CCB. There was increased UAE with $\mathrm{CCB}$ when compared with all the RASI treatments and $\beta$-blocker in the consistency model. However, we did not find increased UAE in CCB than $\beta$-blocker in the inconsistency model (MD 169.66, 95\% CI -11.59, 351.46). Table 5 showed the network comparisons for the SBP (seven studies, five treatments, Supplemental Figure 4). No significant difference was observed in all the treatments either in the consistency model or in the inconsistency model. Table 6 showed network comparisons for the DBP (seven studies, five treatments, Supplemental Figure 5). DBP in all the treatments did not differ. Table 7 showed the network comparisons for the MAP (five studies, five treatments, Supplemental Figure 6). No significant difference was observed in all the treatments either in the consistency model or in the inconsistency model. Table 8 showed the network comparisons for the LVMI (four studies, five treatments, Supplemental Figure 7). LVMI lowering effect was similar in all the treatments either in the consistency model or in the inconsistency model.

In direct comparisons of the primary outcome, the results were almost similar to the network comparisons. There were no statistical difference in the eGFR across the following comparisons (Figure 4): ACEI vs. placebo (one study, 61 participants, MD -8.00, 95\% CI -18.05, 2.05, $P=0.12$ ); ACEI vs. $\beta$-blocker (two studies, 65 participants, MD -5.39, 95\% CI -25.96, 15.17, $P=0.61)$, ACEI vs. CCB (one study, 24 participants, MD -13.00, $95 \%$ CI $-27.85,1.85, P=0.09$ ), ARB vs. CCB (one study, 31 participants, MD 6.30, 95\% CI -8.49, 21.09, $P=0.40)$, ACEI vs. ARB (one study, 32 participants, MD 3.40, 95\% CI -15.91, 22.71, $P=0.78$ ), Dilazep vs. placebo (one study, 22 participants, MD 2.24, 95\% CI -8.05, 12.53, $P=0.67$ ), and $\mathrm{ACEI}+\mathrm{ARB}$ vs. ACEI (two studies, 41 participants, MD -0.63, 95\% CI -4.93, 3.68, $P=0.61)$.

Figure 5 showed the direct comparisons of Scr. No significant difference was observed in direct comparisons of Scr. Figure 6 showed the direct comparisons of UAE. Nutahara et al. [3] reported ARB significantly decreased UAE (24 participants, MD -238.00, 95\% CI -394.61, -81.39, $P=0.003$ ) compared with CCB. Ecder et al. [8] showed that the ACEI decreased UAE significantly compared to the CCB (24 participants, MD -134.00, $95 \%$ CI $-176.01,-91.99, P<0.00001)$. Furthermore, the ARB was associated with lower UAE compared with the ACEI (one study, 20 participants, MD -22, 95\% CI $-28.20,-15.80, P<0.00001)$. Figure 7 showed the direct comparisons of SBP. SBP is lower after the treatment of ACEI than the CCB (one study, 24 participants, MD -5.00, 
$95 \% \mathrm{CI}-8.62,-1.38, P=0.007)$. Figure 8 showed the direct comparisons of DBP. DBP is also lower after the treatment of ACEI than the CCB (one study, 24 participants, MD $-3.00,95 \%$ CI $-5.40,-0.60, P=0.01)$. However, the ACEI significantly increased the DBP compared to the $\beta$-blocker (one study, 37 participants, MD 1.00, 95\% CI 0.35, 1.65, $P=0.002$ ). Figure 9 showed the direct comparisons of MAP. MAP is lower in the treatment of ACEI compared with the CCB (one study, 24 participants, MD -3.00, 95\%
CI $-5.40,-0.60, P=0.007$ ) and the placebo (one study, 61 participants, MD -5.00, 95\% CI -6.29, -3.71, $P<0.00001)$. Figure 10 showed the direct comparisons of LVMI. LVMI was lower after the treatment of ACEI compared with the CCB (one study, 69 participants, MD -27.00, 95\% CI $-43.07,-10.93, P=0.001)$.

Then we performed direct comparisons between the rigorous BP control group (target $<120 / 80 \mathrm{mmHg}$ ) and the standard BP control group (target 120/80-140/90

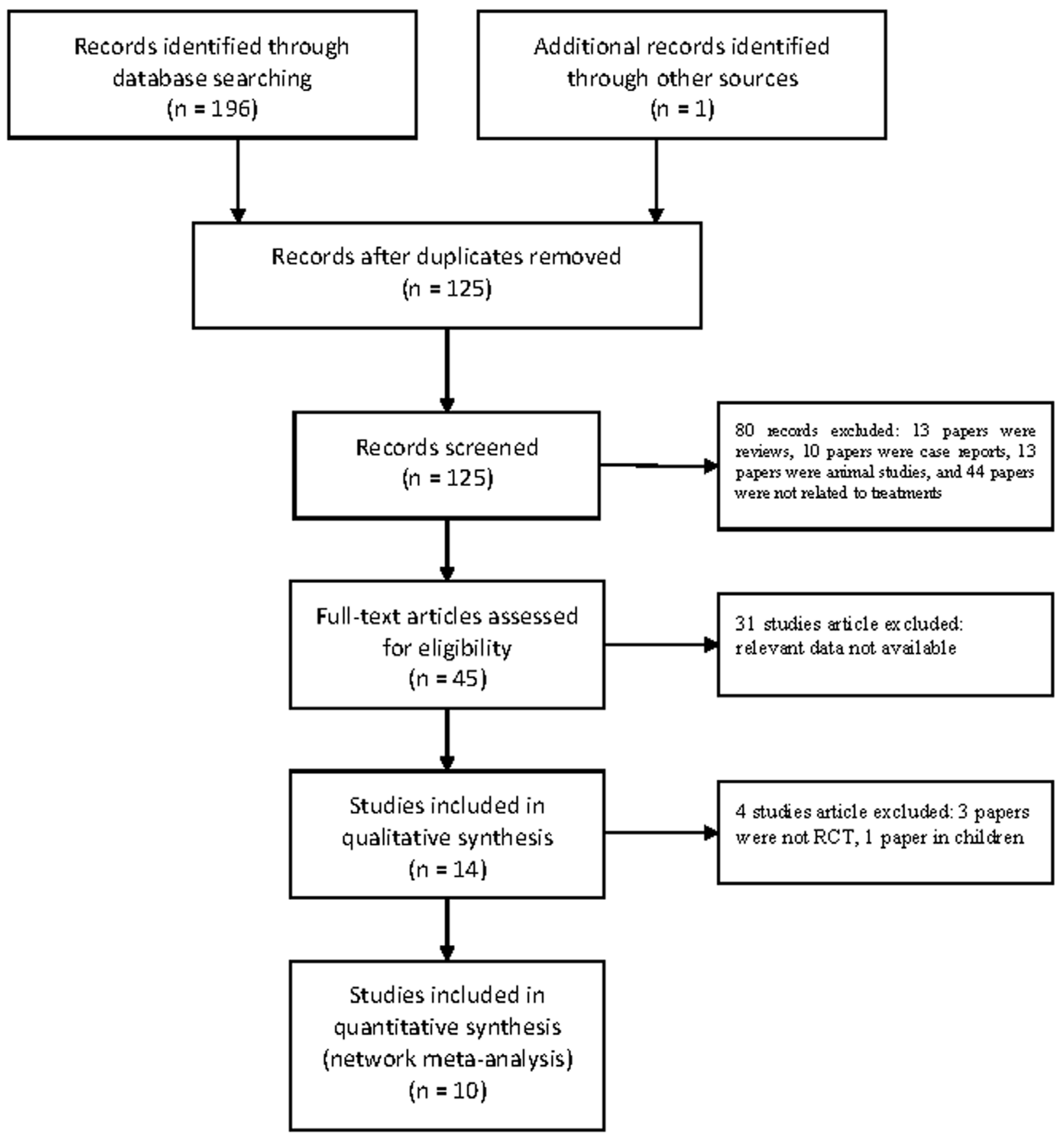

Figure 1: Flow chart of the included studies. 
Table 1: Characteristics of the included trials

\begin{tabular}{|c|c|c|c|c|c|c|c|c|c|c|c|c|c|c|}
\hline Studies & Country & $\begin{array}{l}\text { Randomization } \\
\text { Setting }\end{array}$ & $\begin{array}{r}\text { nDuration } \\
\text { (months) }\end{array}$ & Groups & Number & $\begin{array}{l}\text { Male/female } \\
\text { (N) }\end{array}$ & $\begin{array}{l}\text { Age } \\
\text { (years) }\end{array}$ & $\begin{array}{l}\text { GFR } \\
\mathrm{ml} / \mathrm{min}\end{array}$ & $\begin{array}{l}\text { SBP } \\
\mathrm{mmHg}\end{array}$ & $\begin{array}{l}\text { DBP } \\
\mathrm{mmHg}\end{array}$ & $\begin{array}{l}\text { LVMI } \\
\left(\mathrm{g} / \mathrm{m}^{2}\right)\end{array}$ & $\begin{array}{l}\text { Scr } \\
(\mathrm{mg} / \mathrm{dl})\end{array}$ & $\begin{array}{l}\text { UAE } \\
(\mathrm{mg} / 24 \mathrm{~h})\end{array}$ & Outcomes \\
\hline Ecder & USA & RCT & 60 & Amlodipine & 12 & $8 / 4$ & $43 \pm 3$ & $83 \pm 5$ & $140 \pm 5$ & $93 \pm 3$ & NA & $1.18 \pm 0.06$ & $68 \pm 21$ & (1)(2)(3)(4)(5)(6) \\
\hline 2000 & & Single center & & Enalapril & 12 & $5 / 7$ & $41 \pm 2$ & $77 \pm 6$ & $136 \pm 3$ & $94 \pm 3$ & NA & $1.19 \pm 0.09$ & $23 \pm 4$ & \\
\hline Schrier & USA & RCT & 84 & Enalapril & 49 & NA & $43 \pm 9$ & $79 \pm 31$ & NA & NA & $159 \pm 25$ & NA & NA & (1)(7) \\
\hline 2002 & & Single center & & Amlodipine & 20 & NA & $41 \pm 7$ & $84 \pm 24$ & NA & NA & $159 \pm 25$ & NA & NA & \\
\hline van Dijk & Netherlands & DB RCT & 36 & Enalapril & 13 & $5 / 8$ & $40 \pm 3$ & $80 \pm 9$ & $144 \pm 3$ & $98 \pm 2$ & NA & $1.35 \pm 0.14$ & $39 \pm 31$ & (1) (3) (6) \\
\hline \multirow[t]{3}{*}{2003} & & Single center & & Atenolol & 15 & $5 / 10$ & $33 \pm 3$ & $92 \pm 9$ & $144 \pm 3$ & $96 \pm 1$ & NA & $1.27 \pm 0.14$ & $33 \pm 28$ & \\
\hline & & & & Enalapril & 32 & $11 / 21$ & $36 \pm 2$ & $103 \pm 2$ & $133 \pm 2$ & $88 \pm 2$ & NA & $1.00 \pm 0.02$ & $46 \pm 68$ & \\
\hline & & & & Placebo & 29 & $14 / 15$ & $37 \pm 2$ & $103 \pm 1$ & $133 \pm 2$ & $88 \pm 1$ & NA & $1.00 \pm 0.01$ & $39 \pm 50$ & \\
\hline Nutahara & Japan & RCT & 36 & Amlodipine & 25 & $13 / 12$ & $48.4 \pm 5$ & $71.9 \pm 20.5$ & NA & NA & NA & $1.22 \pm 0.34$ & $148 \pm 187$ & (1)(2)(3)(4)(5) \\
\hline 2005 & & Multicenter & & Candesartan & 24 & $13 / 11$ & $47.3 \pm 5$ & $69.8 \pm 24.6$ & NA & NA & NA & $1.12 \pm 0.30$ & $116 \pm 102$ & \\
\hline Nakamura & Japan & RCT & 6 & Dilazep & 6 & NA & NA & $106.4 \pm 12.2$ & $112 \pm 16$ & NA & NA & $0.80 \pm 0.30$ & $130 \pm 52$ & (1)(2)(3)(4)(5) \\
\hline \multirow[t]{3}{*}{2005} & & Single center & & Placebo & 6 & NA & NA & $102.8 \pm 13.8$ & $114 \pm 14$ & NA & NA & $0.90 \pm 0.40$ & $132 \pm 56$ & \\
\hline & & & & Dilazep & 5 & NA & NA & $102.8 \pm 16.0$ & $158 \pm 12$ & NA & NA & $0.90 \pm 0.40$ & $142 \pm 48$ & \\
\hline & & & & Placebo & 5 & NA & NA & $96.2 \pm 12.8$ & $156 \pm 14$ & NA & NA & $1.00 \pm 0.20$ & $136 \pm 42$ & \\
\hline Zeltner & Germany & RCT & 36 & Ramipril & 17 & $10 / 7$ & $40.7 \pm 2.2$ & $88.0 \pm 9.5$ & $143 \pm 2$ & $93 \pm 2$ & $97.6 \pm 6.1$ & $1.30 \pm 0.19$ & $64.0 \pm 21.6$ & (1)(2)(3)(4)(5)(6)(7) \\
\hline 2008 & & Single center & & Metoprolol & 20 & $7 / 13$ & $40.0 \pm 2.2$ & $87.3 \pm 6.4$ & $142 \pm 2$ & $90 \pm 2$ & $95.0 \pm 4.2$ & $1.16 \pm 0.09$ & $75.3 \pm 22.8$ & \\
\hline Ulusoy & Turkey & RCT & 12 & Losartan & 19 & $6 / 13$ & $51.4 \pm 10.3$ & $375.9 \pm 29.8$ & $156.3 \pm 15.7$ & $98.7 \pm 12.5$ & $117.3 \pm 18.8$ & $1.25 \pm 0.57$ & NA & (1)(2)(4)(5)(6)(7) \\
\hline 2010 & & Single center & & Ramipril. & 13 & $7 / 6$ & $47.7 \pm 7.4$ & $80.1 \pm 9.3$ & $150 \pm 19.6$ & $94.2 \pm 4.9$ & $120.7 \pm 16.3$ & $1.40 \pm 0.77$ & NA & \\
\hline Nakamura & Japan & RCT & 12 & Telmisartan & 10 & $6 / 4$ & $56.6 \pm 6.4$ & $65.9 \pm 6.4$ & $158 \pm 6$ & $96 \pm 5$ & NA & $0.80 \pm 0.09$ & $90.2 \pm 32.5$ & (2)(3)(4)(5) \\
\hline 2012 & & Single center & & Enalapril & 10 & $5 / 5$ & $58.1 \pm 5.6$ & $67.9 \pm 4.5$ & $159 \pm 6$ & $97 \pm 6$ & NA & $0.76 \pm 0.11$ & $92.2 \pm 31.0$ & \\
\hline Schrier & USA & DB RCT & 96 & Lisinopril-telmisartan & n273 & $141 / 142$ & $37.0 \pm 8.3$ & $90.4 \pm 17.5$ & NA & NA & $64.1 \pm 13.2$ & NA & $19.3 \pm 10.2$ & (1)(3)(4)(5)(7) \\
\hline 2014 & & Multicenter & & Lisinopril+placebo & 285 & $142 / 143$ & $36.3 \pm 8.3$ & $92.6 \pm 17.4$ & NA & NA & $63.7 \pm 12.9$ & NA & $17.6 \pm 10.3$ & \\
\hline Torres & USA & DB RCT & 96 & Lisinopril-telmisartan & n244 & $115 / 129$ & $48.6 \pm 8.5$ & $48.5 \pm 11.5$ & NA & NA & NA & $1.5 \pm 0.4$ & $29.7 \pm 29.2$ & (1)(3)(4)(5)(6) \\
\hline 2014 & & Multicenter & & Lisinopril+placebo & 242 & $120 / 122$ & $48.9 \pm 8.1$ & $47.9 \pm 12.2$ & NA & NA & NA & $1.6 \pm 0.4$ & $28.1 \pm 30.6$ & \\
\hline
\end{tabular}

SB, single-blinded; DB, double-blinded; RCT, randomized controlled trial; eGFR glomerular filtration rate; SBP, systolic blood pressure; DBP, diastolic blood pressure; LVMI, left ventricular mass index; UAE, urinary albumin excretion; Scr, serum creatinine; NA, not available; Outcomes: (1) eGFR, (2) Scr, (3) UAE, (4) SBP, 5 DBP, (6) MAP, 7 LVMI.

Table 2: The effects of the antihypertensive treatments in the eGFR.

\begin{tabular}{|l|l|l|l|l|}
\hline ACEI & $-0.81(-16.34,14.34)$ & $3.79(-19.07,26.53)$ & $1.61(-12.34,22.27)$ & $7.75(-14.21,28.48)$ \\
\hline $0.95(-14.77,17.07)$ & ACEI+ARB & $4.69(-21.82,32.15)$ & $2.35(-16.75,29.26)$ & $3.65(-24.84,32.68)$ \\
\hline$-5.88(-26.54,18.72)$ & $-6.66(-32.71,22.42)$ & ARB & $-1.71(-28.01,28.71)$ & $-1.15(-22.28,20.72)$ \\
\hline$-1.95(-23.22,12.13)$ & $-2.75(-30.53,17.21)$ & $3.59(-29.61,28.07)$ & $\beta$-blocker & $0.61(-30.58,28.61)$ \\
\hline$-6.23(-26.17,15.48)$ & $-7.19(-32.86,19.76)$ & $-0.22(-22.72,20.78)$ & $-4.08(-27.62,26.48)$ & CCB \\
\hline
\end{tabular}

Data was listed as MD with 95\% CI. Effect estimates from the network meta-analysis in the consistency model occupy the bottom left part of the diagram, and the estimates from the inconsistency model occupy the top right part of the diagram. The diagonal corresponds to the comparison. The data should be read from left to right in the bottom left part of the diagram, and from right to left in the top right part of the diagram.

Table 3: The effects of the antihypertensive treatments in the Scr.

\begin{tabular}{|l|l|l|l|}
\hline ACEI & $-0.15(-0.58,0.29)$ & $-0.18(-0.75,0.38)$ & $0.02(-0.36,0.53)$ \\
\hline $0.16(-0.25,0.57)$ & ARB & $-0.03(-0.74,0.67)$ & $0.26(-0.27,0.83)$ \\
\hline $0.17(-0.40,0.77)$ & $0.00(-0.69,0.71)$ & $\beta$-blocker & $0.29(-0.46,1.09)$ \\
\hline$-0.04(-0.53,0.35)$ & $-0.21(-0.72,0.25)$ & $-0.21(-1.00,0.46)$ & CCB \\
\hline
\end{tabular}

Data was listed as MD with 95\% CI. Effect estimates from the network meta-analysis in the consistency model occupy the bottom left part of the diagram, and the estimates from the inconsistency model occupy the top right part of the diagram. The diagonal corresponds to the comparison. The MD and 95\% CI for the comparisons should be read from left to right. The data should be read from left to right in the bottom left part of the diagram, and from right to left in the top right part of the diagram. 


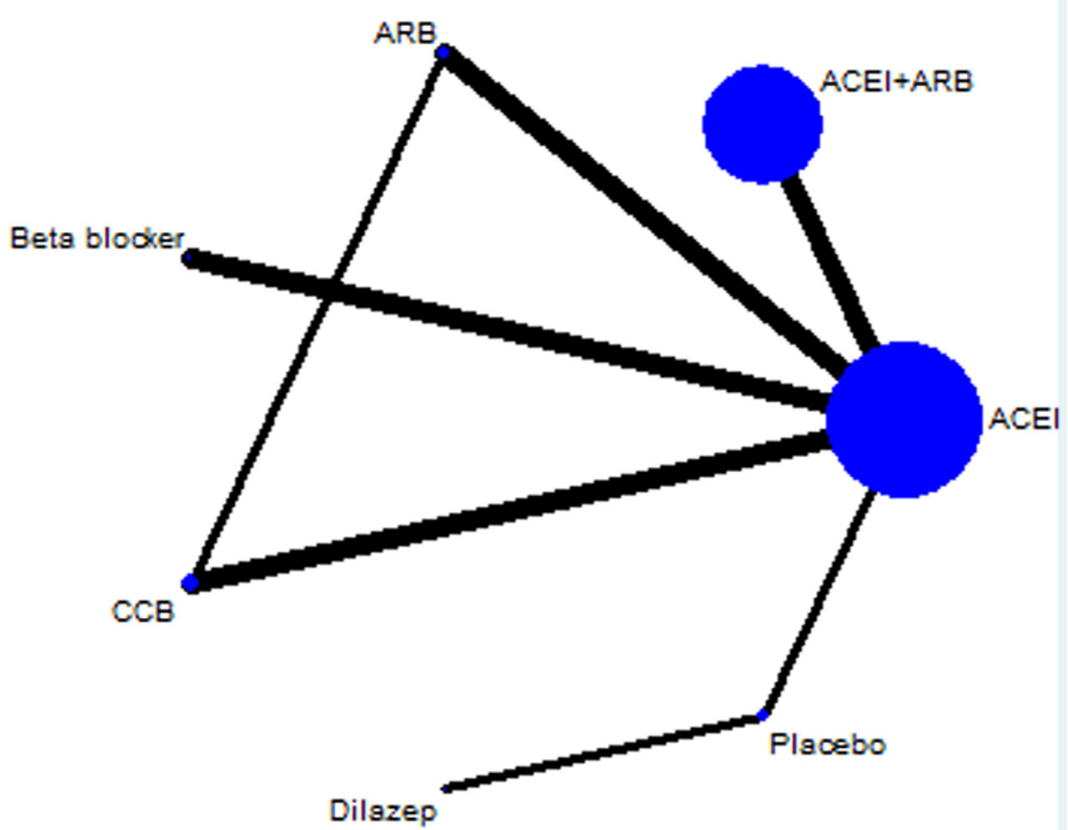

Figure 2: Network of antihypertensive drugs in ADPKD. The size of treatment nodes (blue circles) reflected the number of studies. The thickness of lines represented the number of trials in that comparison. ARB: angiotensin-receptor blocker. ACEI: angiotensinconverting-enzyme inhibitor. CCB: calcium-channel blocker.
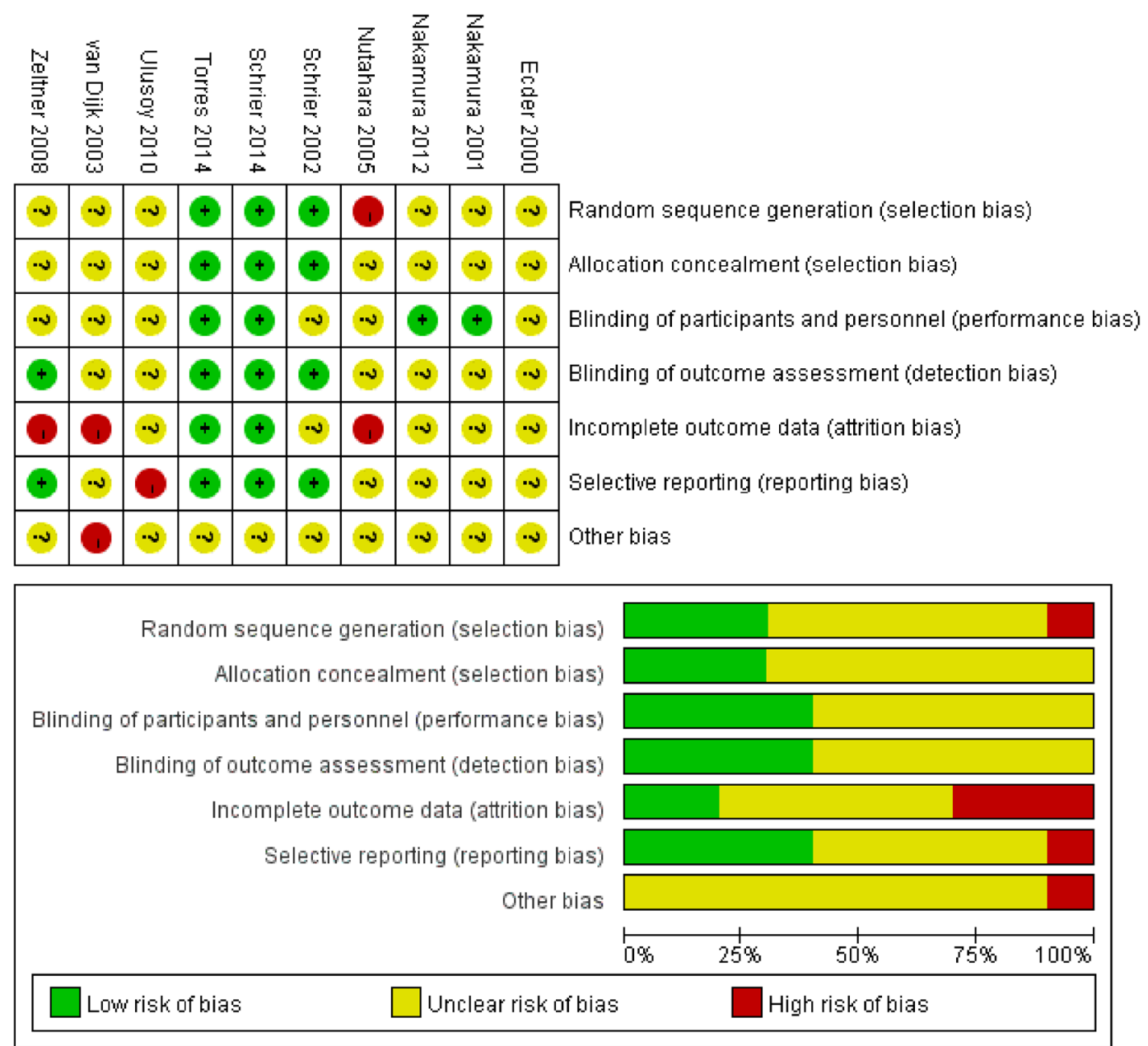

Figure 3: Risk of bias summary for the included studies. 
$\mathrm{mm} \mathrm{Hg}$ ). The results found the rigorous BP group was associated with a greater decrease in LVMI (three studies, 517 participants, MD -14.56, 95\% CI -27.06, -2.06, $P=0.02$ ) compared with the standard BP group (Figure 10). However, the eGFR was similar between the two groups (three studies, 261 participants, MD -6.39, 95\% CI $-17.67,4.90, P=0.27$ ) (Figure 4). UAE tended to be less in the rigorous BP group (two studies, 208 participants, MD $-38.6,95 \%$ CI $-101.61,24.4, P=0.23)$, but the result was not significant (Figure 6).

Bayesian probability analysis found the ARB had $34 \%$ probability to be the best treatment in eGFR. The ranking sequence was shown in Table 9. ARB also ranked first in the UAE and the SBP. B-blocker ranked first in the Scr and the LVMI. ACEI+ARB ranked first in the DBP and the MAP.

Sensitivity analysis of by changing different models got similar results for all the outcomes in direct

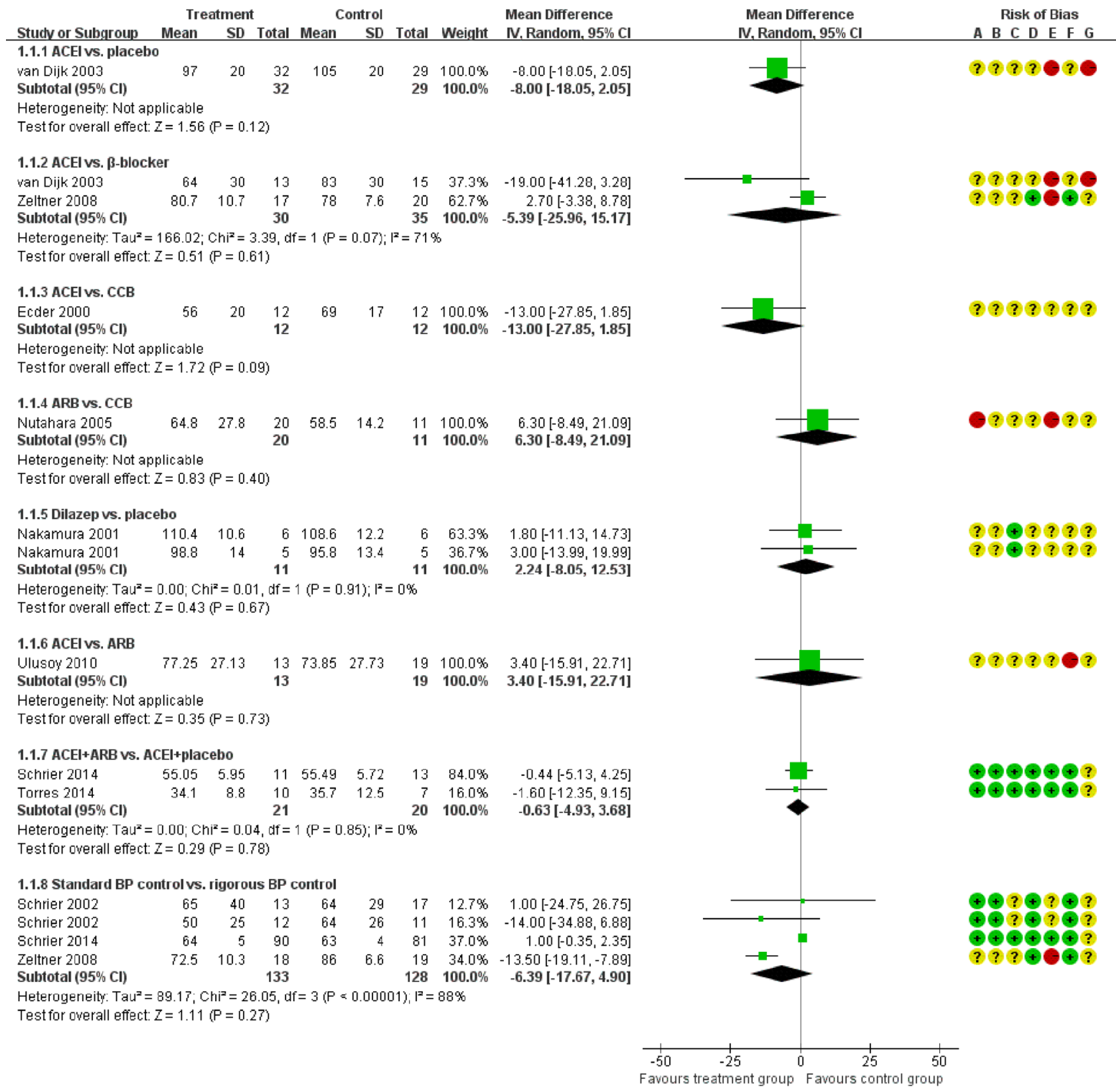

Risk of bias leqend

(A) Random sequence generation (selection bias)

(B) Allocation concealment (selection bias)

(C) Blinding of participants and personnel (performance bias)

(D) Blinding of outcome assessment (detection bias)

(E) Incomplete outcome data (attrition bias)

(F) Selective reporting (reporting blas)

(G) Other bias

Figure 4: Meta-analysis of all the antihypertensive treatments in eGFR. 
Table 4: The effects of the antihypertensive treatments in the UAE.

\begin{tabular}{|c|c|c|c|c|}
\hline ACEI & $-4.78(-98.28,86.41)$ & $-26.38(-158.54,75.14)$ & $9.62(-84.67,102.61)$ & $\begin{array}{l}142.47 \\
266.82)\end{array}$ \\
\hline $4.87(-75.73,97.85)$ & $\mathrm{ACEI}+\mathrm{ARB}$ & $-21.98(-188.63,117.60)$ & $14.48(-117.15,143.84)$ & \begin{tabular}{|l}
184.71 \\
$366.13)$
\end{tabular} \\
\hline $29.95(-61.87,145.72)$ & $25.54(-104.17,164.39)$ & $\mathrm{ARB}$ & $35.57(-98.63,199.18)$ & $\begin{array}{ll}209.14 & \text { (68.09, } \\
367.05) & \\
\end{array}$ \\
\hline$-9.49(-96.03,75.27)$ & $-14.76(-140.97,103.48)$ & $-39.27(-185.32,78.06)$ & $\beta$-blocker & $\begin{array}{ll}169.66 & (-11.59, \\
351.46) & \end{array}$ \\
\hline $\begin{array}{l}-146.03(-263.33 \\
-47.16)\end{array}$ & $\begin{array}{ll}-150.86 & (-305.70 \\
-26.34) & \end{array}$ & $-177.55(-317.05,-74.83)$ & $-135.99(-284.14,-3.62)$ & $\mathrm{CCB}$ \\
\hline
\end{tabular}

Data was listed as MD with 95\% CI. Effect estimates from the network meta-analysis in the consistency model occupy the bottom left part of the diagram, and the estimates from the inconsistency model occupy the top right part of the diagram. The diagonal corresponds to the comparison. The MD and 95\% CI for the comparisons should be read from left to right. Significant results are underlined and in bold. The data should be read from left to right in the bottom left part of the diagram, and from right to left in the top right part of the diagram.

Table 5: The effects of the antihypertensive treatments in the SBP.

\begin{tabular}{|l|l|l|l|l|}
\hline ACEI & $-0.63(-4.68,4.14)$ & $-1.60(-6.37,3.05)$ & $1.00(-4.36,6.33)$ & $4.70(-1.19,10.13)$ \\
\hline $0.66(-4.21,4.75)$ & ACEI+ARB & $-1.01(-7.65,5.05)$ & $1.67(-5.68,8.34)$ & $5.07(-3.93,12.81)$ \\
\hline $1.50(-3.18,6.22)$ & $0.85(-5.22,7.56)$ & ARB & $2.56(-4.44,9.66)$ & $6.08(-2.23,13.75)$ \\
\hline$-1.00(-6.23,4.32)$ & $-1.67(-8.19,5.68)$ & $-2.48(-9.35,4.55)$ & $\beta$-blocker & $3.46(-5.77,11.95)$ \\
\hline$-4.70(-9.96,1.30)$ & $-5.40(-11.90,2.62)$ & $-6.17(-12.87,1.00)$ & $-3.74(-11.02,4.35)$ & CCB \\
\hline
\end{tabular}

Data was listed as MD with 95\% CI. Effect estimates from the network meta-analysis in the consistency model occupy the bottom left part of the diagram, and the estimates from the inconsistency model occupy the top right part of the diagram. The diagonal corresponds to the comparison. The MD and 95\% CI for the comparisons should be read from left to right. The data should be read from left to right in the bottom left part of the diagram, and from right to left in the top right part of the diagram.

Table 6: The effects of the antihypertensive treatments in the DBP.

\begin{tabular}{|l|l|l|l|l|}
\hline ACEI & $-1.31(-8.62,3.40)$ & $-0.64(-5.95,4.99)$ & $-1.00(-8.38,6.35)$ & $2.75(-4.96,9.68)$ \\
\hline $1.13(-3.31,8.38)$ & ACEI+ARB & $0.71(-6.04,10.25)$ & $0.21(-8.00,11.17)$ & $3.80(-7.42,15.63)$ \\
\hline $0.69(-4.95,5.80)$ & $-0.53(-10.22,5.86)$ & ARB & $-0.35(-9.79,8.72)$ & $2.94(-8.11,12.93)$ \\
\hline $0.93(-6.36,8.31)$ & $0.04(-11.16,7.80)$ & $0.26(-8.60,9.57)$ & $\beta$-blocker & $3.34(-9.22,14.97)$ \\
\hline$-2.81(-9.45,4.74)$ & $-3.84(-14.08,4.08)$ & $-3.44(-11.26,5.65)$ & $-3.77(-13.41,6.82)$ & CCB \\
\hline
\end{tabular}

Data was listed as MD with 95\% CI. Effect estimates from the network meta-analysis in the consistency model occupy the bottom left part of the diagram, and the estimates from the inconsistency model occupy the top right part of the diagram. The diagonal corresponds to the comparison. The MD and $95 \% \mathrm{CI}$ for the comparisons should be read from left to right. The data should be read from left to right in the bottom left part of the diagram, and from right to left in the top right part of the diagram.

Table 7: The effects of the antihypertensive treatments in the MAP.

\begin{tabular}{|l|l|l|l|l|}
\hline ACEI & $-4.85(-17.71,8.31)$ & $-2.55(-10.30,5.13)$ & $0.83(-3.68,5.83)$ & $3.04(-3.97,9.98)$ \\
\hline $4.26(-8.85,17.31)$ & ACEI+ARB & $2.18(-12.90,17.24)$ & $5.65(-8.14,19.72)$ & $7.85(-6.72,22.43)$ \\
\hline $2.70(-5.13,10.37)$ & $-1.59(-16.66,13.60)$ & ARB & $3.39(-5.54,12.63)$ & $5.62(-4.93,16.08)$ \\
\hline$-0.83(-5.78,3.70)$ & $-5.13(-19.00,8.59)$ & $-3.55(-12.69,5.48)$ & $\beta$-blocker & $2.20(-6.06,10.42)$ \\
\hline$-2.93(-9.99,4.12)$ & $-7.27(-22.16,7.37)$ & $-5.65(-15.88,4.73)$ & $-2.14(-10.48,6.72)$ & CCB \\
\hline
\end{tabular}

Data was listed as MD with 95\% CI. Effect estimates from the network meta-analysis in the consistency model occupy the bottom left part of the diagram, and the estimates from the inconsistency model occupy the top right part of the diagram. The diagonal corresponds to the comparison. The MD and 95\% CI for the comparisons should be read from left to right.

The data should be read from left to right in the bottom left part of the diagram, and from right to left in the top right part of the diagram. 
comparisons. Sensitivity analysis of direct comparisons by excluding each study one by one was consistent with the former results. Heterogeneity of direct comparisons was high in the rigorous BP vs. standard BP group, because the included studies used log transformations in the results. Heterogeneity in the network comparisons was mainly from the ACEI-ARB-CCB loop, so we checked the heterogeneity through the node-splitting (Table 10). There was no significant heterogeneity in the node-splitting.

\section{DISCUSSION}

This study provided evidences for the antihypertensive treatments from 10 RCTs evaluating six interventions in adult patients with ADPKD. Overall, network comparisons and direct comparisons both indicated there was currently insufficient evidence of an association between lowering BP and the surrogate measures of kidney.

All the treatments did not differ in eGFR, Scr, SBP, DBP, MAP, and LVMI in network comparisons.
Compared with $\beta$-blocker or CCB, RASIs did not show different effects on the renal function. ACEI was not associated with significantly protective effects on eGFR and UAE when compared with placebo. However, ACEI significantly decreased SBP, DBP, MAP and LVMI when compared with CCB. Significantly increased UAE was observed in CCB compared with RASI treatments. No significant outcome was found in Dilazep compared with placebo. The rigorous BP control was associated with lower LVMI than the standard BP control. ARB may be relatively the most suitable treatment for eGFR, UAE and $\mathrm{SBP}$ in ADPKD.

RASIs are the first-line treatments for hypertension in ADPKD till now [16]. However, little beneficial effect of RASIs in renal function was found in ADPKD patients in the past [17]. Therapeutic effects of RASI in renal function might be limited due to massive cystic involvement. EGFR in the majority of ADPKD patients remained steady until the late stage of the disease [18]. Combination of ACEI and ARB which was supposed to solve the compensatory feedback showed similar

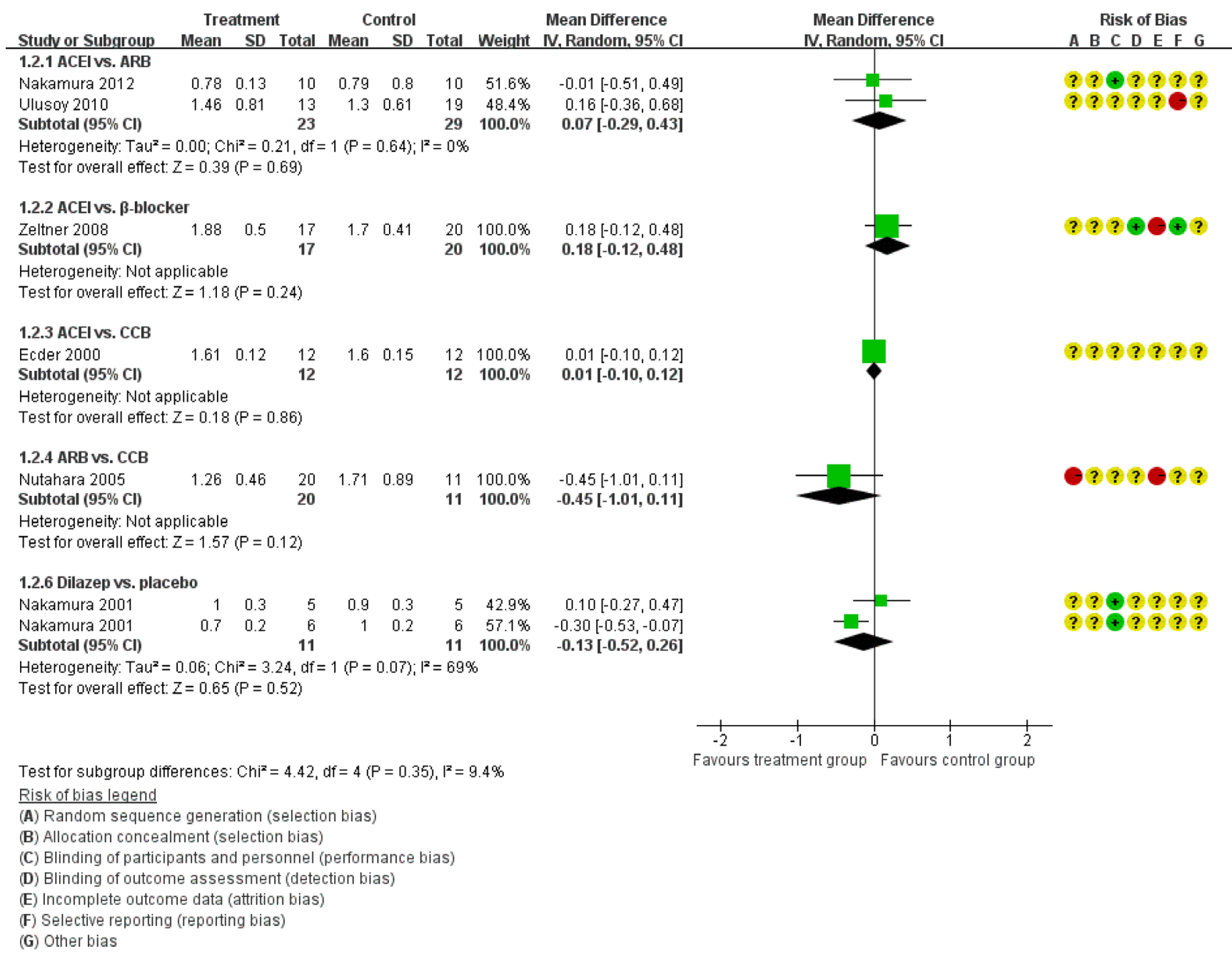

Figure 5: Meta-analysis of all the antihypertensive treatments in Scr. 
treatment effects of eGFR and TKV when compared with the ACEI monotherapy $[1,2]$.

UAE reflects the level of glomerular proteinuria, which is considered as a marker of glomerular injury [19]. ACEI is widely used in CKD to reduce the albuminuria mainly through lowering the intra-glomerular pressure [20]. Protective effects of ACEI were almost found in patients with chronic glomerulonephritis or proteinuria $>$ $2 \mathrm{~g} / 24 \mathrm{~h}$ which did not always happen in ADPKD [21].
ADPKD patients were always accompanied with low levels of UAE ( $<2 \mathrm{~g} / 24 \mathrm{~h})$. Therefore the anti-albuminuria effect of the ACEI still need large-scale studies to prove.

CCB was associated with increased UAE than RASIs $[3,8,10]$. We noticed that the CCB used in the trials was amlodipine (L-type CCB). CCBs varied in their effects of glomerular arterioles. T- or N-channel receptors mainly existed on the afferent and efferent arteriole, while L-channel receptors predominantly existed on the afferent

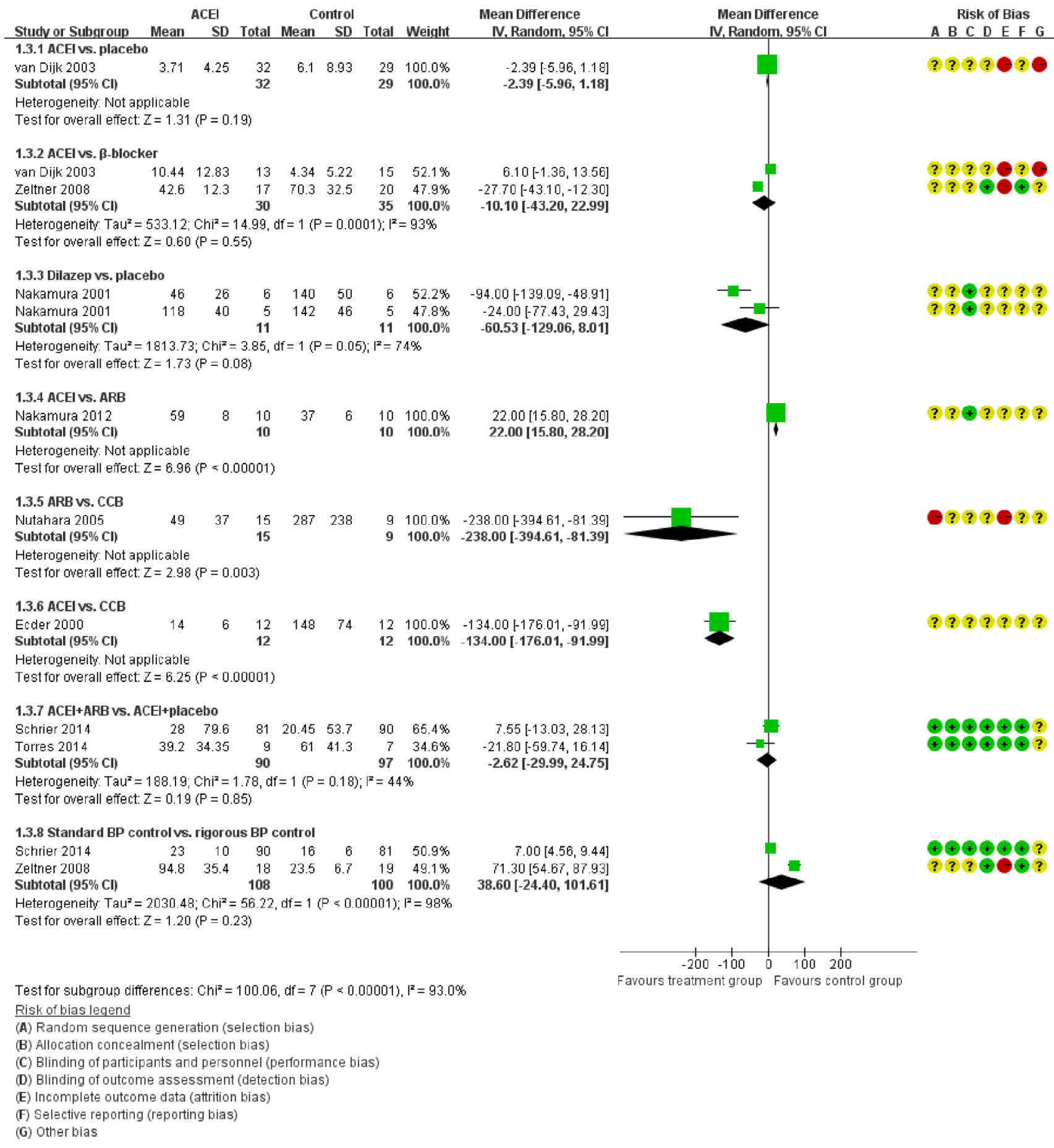

Figure 6: Meta-analysis of all the antihypertensive treatments in UAE. 
arteriole. T-/N-channel blockade led to a reduction of intra-glomerular pressure and accordingly decreased UAE levels, while blockade of L-channel receptors led to an increase of UAE [22]. On the other hand, cytosolic $\mathrm{Ca}^{2+}$ depletion caused by $P K D 1 / 2$ mutation could activate cyclic adenosine monophosphate (cAMP) signal pathway and accelerate cystic proliferation in ADPKD [23,24]. CCB might aggravate the $\mathrm{Ca}^{2+}$ depletion of the tubules and activate the cAMP pathway. However, this hypothesis needed to be testified.

B-blockers treatment was limited and uncertain according to the existing outcomes. B-blockers could inhibit RAAS activation by suppressing renin release. Evidence about $\beta$-blockers in ADPKD still needs more studies to prove.

LVMI is known as cardiovascular risk factor for morbidity or mortality in ADPKD patients [19]. Left ventricular hypertrophy frequently occurs in ADPKD patients with hypertension. LVMI decrease of hypertensive patients could bring benefits in reduced cardiovascular risk and mortality. Only rigorous BP control was found to be associated with obvious decline in LVMI compared with the standard BP control. Moreover, the HALT-PKD study found rigorous $\mathrm{BP}$ control could slow TKV significantly in the patients with early ADPKD $[1,2]$. However, the eGFR and the UAE were not significant in the rigorous BP control group.

There were few data on patient relevant endpoints, such as end stage renal disease, need for dialysis/ transplantation and mortality in addition to adverse drug effects. Zeltner et al. [4] reported no difference between ACEI vs. $\beta$-blocker in the need for dialysis/transplantation and the risk of cardiovascular events. Nutahara et al. [3] reported no difference between $\mathrm{ARB}$ vs. $\mathrm{CCB}$ in the risk of doubling of Scr.

This study had several limitations. First, the sample

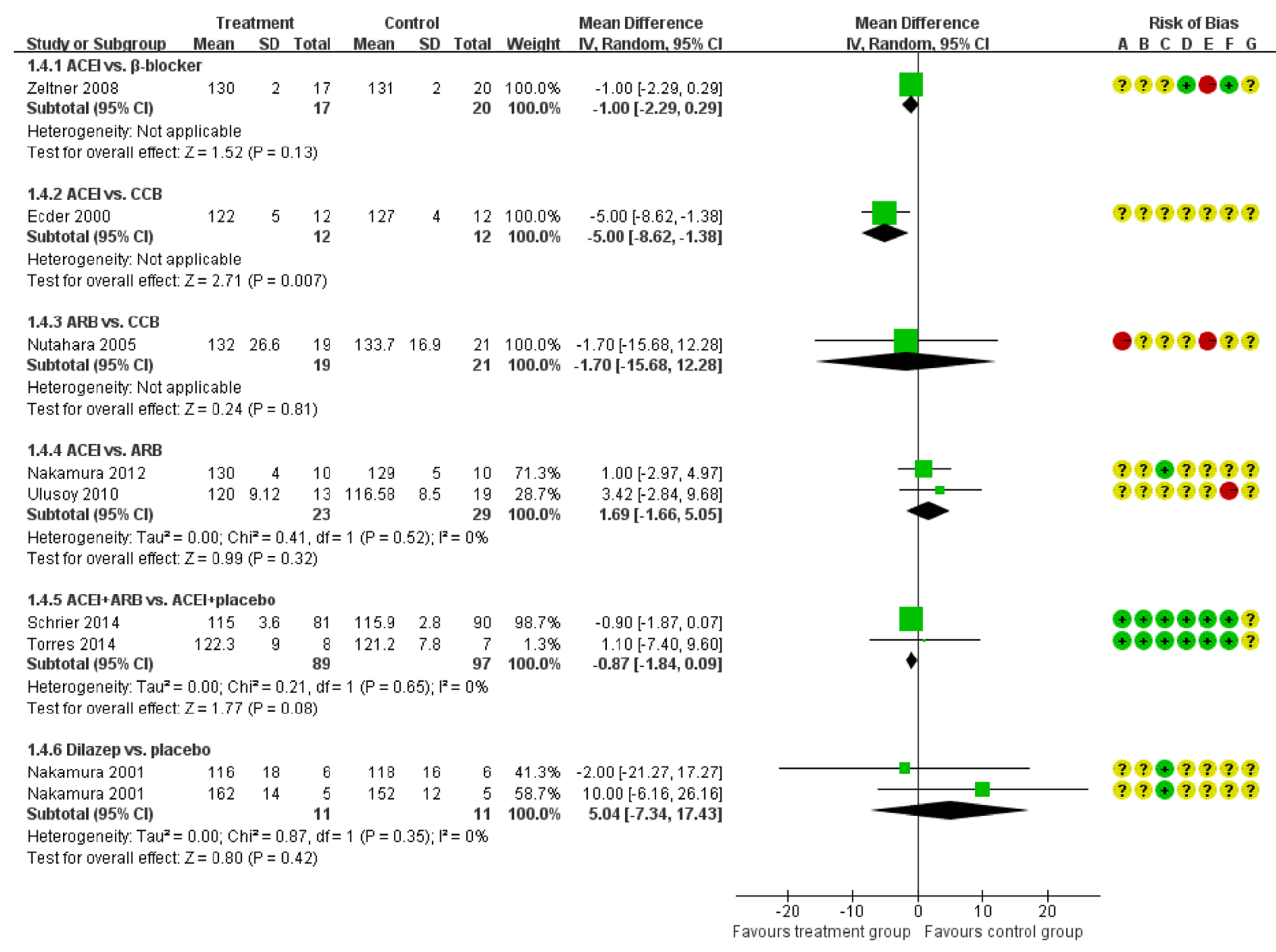

Risk of bias legend

(A) Random sequence generation (selection bias)

(B) Allocation concealment (selection bias)

(C) Blinding of participants and personnel (performance bias)

(D) Blinding of outcome assessment (detection bias)

(E) Incomplete outcome data (attrition bias)

(F) Selective reporting (reporting bias)

(G) Other bias

Figure 7: Meta-analysis of all the antihypertensive treatments in SBP. 
Table 8: The effects of the antihypertensive treatments in the LVMI.

\begin{tabular}{|l|l|l|l|l|}
\hline ACEI & $0.41(-34.15,35.78)$ & $5.14(-31.10,40.07)$ & $-2.58(-37.76,31.34)$ & $27.10(-9.23,64.91)$ \\
\hline$-0.29(-34.40,33.07)$ & ACEI+ARB & $4.82(-45.86,53.24)$ & $-2.79(-52.75,44.60)$ & $26.73(-22.61,77.88)$ \\
\hline$-5.14(-41.44,31.46)$ & $-4.85(-54.72,44.27)$ & ARB & $-7.73(-56.80,41.13)$ & $21.73(-27.05,74.00)$ \\
\hline $2.13(-32.01,35.90)$ & $2.48(-45.68,51.30)$ & $7.27(-42.40,56.31)$ & $\beta$-blocker & $29.70(-19.46,82.01)$ \\
\hline$-27.08(-63.78,8.59)$ & $-26.60(-76.63,22.67)$ & $-21.36(-74.09,28.23)$ & $-29.11(-79.47,19.34)$ & CCB \\
\hline
\end{tabular}

Data was listed as MD with $95 \%$ CI. Effect estimates from the network meta-analysis in the consistency model occupy the bottom left part of the diagram, and the estimates from the inconsistency model occupy the top right part of the diagram.

The diagonal corresponds to the comparison. The MD and 95\% CI for the comparisons should be read from left to right.

The data should be read from left to right in the bottom left part of the diagram, and from right to left in the top right part of the diagram.

Table 9: The rank sequence of the antihypertensive treatments in the outcomes.

\begin{tabular}{|l|l|l|l|l|l|l|l|}
\hline Drug & eGFR & Scr & UAE & SBP & DBP & MAP & LVMI \\
\hline ACEI & Rank 3 & Rank 3 & Rank 3 & Rank 3 & Rank 3 & Rank 3 & Rank 2 \\
\hline ACEI+ARB & Rank 4 & & Rank 2 & Rank 2 & Rank 1 & Rank 1 & Rank 3 \\
\hline ARB & Rank 1 & Rank 2 & Rank 1 & Rank 1 & Rank 4 & Rank 2 & Rank 4 \\
\hline$\beta$-blocker & Rank 5 & Rank 1 & Rank 4 & Rank 4 & Rank 2 & Rank 4 & Rank 1 \\
\hline CCB & Rank 2 & Rank 4 & Rank 5 & Rank 5 & Rank 5 & Rank 5 & Rank 5 \\
\hline
\end{tabular}

Rank 1 was the best. The bigger number of the rank, the worse rank. Rank 1 was underlined and in bold.
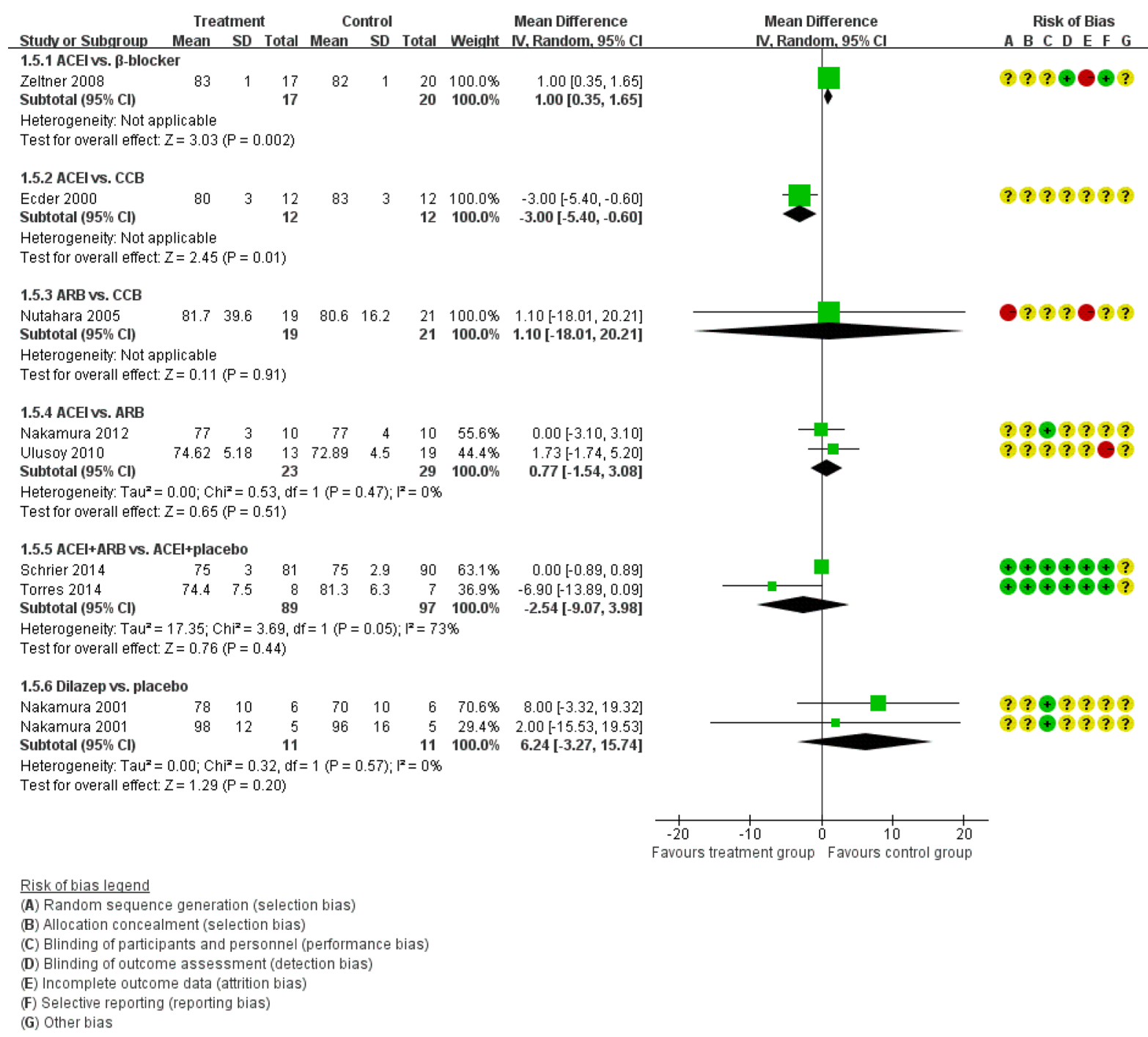

Figure 8: Meta-analysis of all the antihypertensive treatments in DBP. 


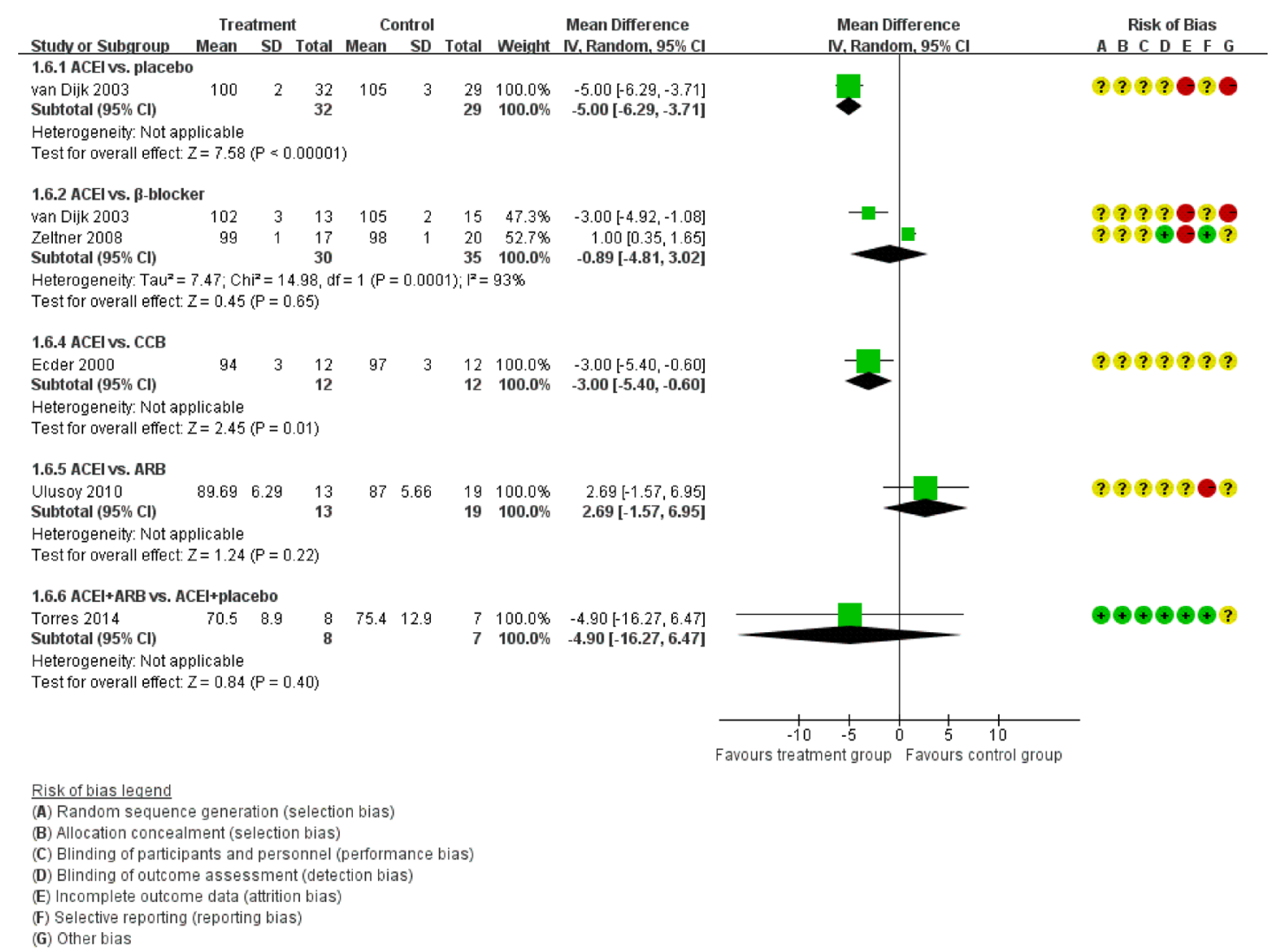

Figure 9: Meta-analysis of all the antihypertensive treatments in MAP.

\begin{tabular}{|c|c|c|c|c|c|c|c|c|c|c|}
\hline \multirow[b]{2}{*}{ Study or Subgroup } & \multicolumn{2}{|c|}{ RAAS-I } & \multicolumn{4}{|c|}{ Control } & \multicolumn{2}{|r|}{ Mean Difference } & \multirow{2}{*}{$\begin{array}{l}\text { Mean Difference } \\
\text { IV, Random, } 95 \% \mathrm{Cl}\end{array}$} & \multirow{2}{*}{$\begin{array}{l}\text { Risk of Bias } \\
\text { A B C DEF G }\end{array}$} \\
\hline & Mean & & Total & Mean & SD & Total & Weight & IV, Random. $95 \% \mathrm{Cl}$ & & \\
\hline \multicolumn{10}{|c|}{ 1.7.3 ACEI+ARB vs. ACEI } & \multirow{3}{*}{$\oplus \oplus \oplus \oplus \oplus \oplus$ ? } \\
\hline Schrier 2014 & 59.2 & 12.74 & 208 & 58.9 & 12.85 & 219 & $100.0 \%$ & $0.30[-2.13,2.73]$ & & \\
\hline Subtotal $(95 \% \mathrm{Cl})$ & & & 208 & & & 219 & $100.0 \%$ & $0.30[-2.13,2.73]$ & & \\
\hline \multicolumn{11}{|c|}{ Heterogeneity: Not applicable } \\
\hline \multicolumn{11}{|c|}{ Test for overall effect: $Z=0.24(P=0.81\rangle$} \\
\hline \multicolumn{11}{|l|}{ 1.7.4 ACElvs. ARB } \\
\hline Ulus oy 2010 & 101.69 & 15.25 & 13 & 106.88 & 20.12 & 19 & $100.0 \%$ & $-5.19[-17.46,7.08]$ & & \multirow[t]{4}{*}{ ???2?ด? } \\
\hline Subtotal $(95 \% \mathrm{Cl})$ & & & 13 & & & 19 & $100.0 \%$ & $-5.19[-17.46,7.08]$ & & \\
\hline \multirow{2}{*}{\multicolumn{10}{|c|}{$\begin{array}{l}\text { Heterogeneity: Not applicable } \\
\text { Test for overall effect: } Z=0.83(P=0.41)\end{array}$}} & \\
\hline & & & & & & & & & & \\
\hline \multicolumn{11}{|c|}{ 1.7.5 ACE vs. $\beta$-blocker } \\
\hline Zeltner 2008 & 102.6 & 6.8 & 17 & 100.3 & 5.4 & 20 & $100.0 \%$ & $2.30[-1.71,6.31]$ & & \multirow[t]{4}{*}{ ???๑९๑? } \\
\hline Subtotal $(95 \% \mathrm{Cl})$ & & & 17 & & & 20 & $100.0 \%$ & $2.30[-1.71,6.31]$ & & \\
\hline \multicolumn{10}{|c|}{ Heterogeneity: Not applicable } & \\
\hline \multicolumn{10}{|c|}{ Test for overall effect: $Z=1.13(\mathrm{P}=0.26)$} & \\
\hline \multicolumn{11}{|l|}{ 1.7.6 ACElvs. CCB } \\
\hline Schrier 2002 & 106 & 25 & 49 & 133 & 33 & 20 & $100.0 \%$ & $-27.00[-43.07,-10.93]$ & & \multirow[t]{4}{*}{$\odot \odot ? \odot ? \odot ?$} \\
\hline Subtotal (95\% Cl) & & & 49 & & & 20 & $100.0 \%$ & $-27.00[-43.07,-10.93]$ & & \\
\hline \multicolumn{10}{|c|}{ Heterogeneity: Not applicable } & \\
\hline \multicolumn{10}{|c|}{ Test for overall effect: $Z=3.29(\mathrm{P}=0.0010)$} & \\
\hline \multicolumn{10}{|c|}{ 1.7.8 Standard BP controlvs. rigorous BP control } & \multirow{16}{*}{ 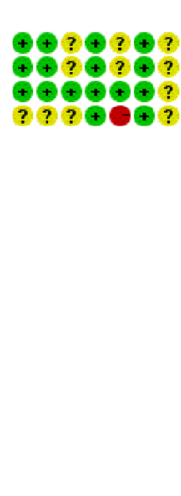 } \\
\hline Schrier 2002 & 134 & 27 & 13 & 108 & 23 & 17 & $19.5 \%$ & $26.00[7.70,44.30]$ & & \\
\hline Schrier 2002 & 112 & 31 & 12 & 99 & 29 & 11 & $14.7 \%$ & $13.00[-11.52,37.52]$ & & \\
\hline Echrier 2014 & 61 & 15 & 220 & 57.5 & 15 & 207 & $33.1 \%$ & $3.50[0.65,6.35]$ & $=$ & \\
\hline Zeltner 2008 & 110.5 & 6.3 & 18 & 90.9 & 4.7 & 19 & $32.7 \%$ & $19.60[16.00,23.20]$ & $\rightarrow-$ & \\
\hline Subtotal $(95 \% \mathrm{Cl})$ & & & 263 & & & 254 & $100.0 \%$ & $14.56[2.06,27.06]$ & & \\
\hline \multicolumn{10}{|c|}{$\begin{array}{l}\text { Heterogeneity: } \text { Tau }^{2}=120.89 ; \mathrm{Ch}^{2}=50.39, \mathrm{df}=3(\mathrm{P}<0.00001) ; \mathrm{I}^{2}=94 \% \\
\text { Test for overall effect: } Z=2.28(\mathrm{P}=0.02)\end{array}$} & \\
\hline \multicolumn{9}{|c|}{ Test for subgroup differences: $\mathrm{Ch}^{2}=17.73, \mathrm{df}=4(\mathrm{P}=0.001), \mathrm{P}^{2}=77.4 \%$} & $\begin{array}{cccccc} & -10 & -10 & 0 & 10 & 20 \\
\text { Favours treatment group } & \text { Favours control group }\end{array}$ & \\
\hline Risk of bias legend & 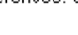 & - & 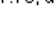 & 10 & 0.001 & - & & & & \\
\hline (A) Random sequer & e generat & tion (sel & lection & bias) & & & & & & \\
\hline (B) Allocation conce & ment (sel & lection b & bias) & & & & & & & \\
\hline (C) Blinding of partic & ants and & person & nel (pe & Iformanc & ce bias) & & & & & \\
\hline (D) Blinding of outco & le assess & sment $(c)$ & detectic & on bias) & & & & & & \\
\hline (E) Incomplete outco & e data (a & tttrition $\mathrm{b}$ & ias) & & & & & & & \\
\hline (F) Selective reportin & (reporting & g bias) & & & & & & & & \\
\hline (G) Other bias & & & & & & & & & & \\
\hline
\end{tabular}

Figure 10: Meta-analysis of all the antihypertensive treatments in LVMI. 
Table 10: The heterogeneity of the antihypertensive treatments in the network comparisons

\begin{tabular}{|c|c|c|c|c|}
\hline Name & Direct Effect & Indirect Effect & Overall & $P$-Value \\
\hline \multicolumn{5}{|c|}{ Node-splittings of eGFR } \\
\hline ACEI, ARB & $-3.68(-31.24,24.03)$ & $18.73(-16.14,54.44)$ & $5.88(-18.72,26.54)$ & 0.27 \\
\hline ACEI, CCB & $13.24(-12.01,38.58)$ & $-10.33(-46.59,27.04)$ & $6.23(-15.48,26.17)$ & 0.27 \\
\hline $\mathrm{ARB}, \mathrm{CCB}$ & $-6.05(-30.78,19.10)$ & $15.85(-20.44,52.61)$ & $0.22(-20.78,22.72)$ & 0.30 \\
\hline \multicolumn{5}{|c|}{ Node-splittings of Scr } \\
\hline ACEI, ARB & $-0.07(-0.56,0.44)$ & $-0.46(-1.40,0.46)$ & $-0.16(-0.57,0.25)$ & 0.40 \\
\hline ACEI, CCB & $-0.01(-0.54,0.51)$ & $0.38(-0.52,1.28)$ & $0.04(-0.35,0.53)$ & 0.41 \\
\hline $\mathrm{ARB}, \mathrm{CCB}$ & $0.44(-0.28,1.19)$ & $0.06(-0.67,0.79)$ & $0.21(-0.25,0.72)$ & 0.41 \\
\hline \multicolumn{5}{|c|}{ Node-splittings of UAE } \\
\hline ACEI, ARB & $-22.14(-198.76,152.03)$ & $-116.21(-382.10,163.42)$ & $-29.95(-145.72,61.87)$ & 0.42 \\
\hline ACEI, CCB & $134.31(-27.00,289.65)$ & $216.96(-34.52,464.40)$ & $146.03(47.16,263.33)$ & 0.47 \\
\hline $\mathrm{ARB}, \mathrm{CCB}$ & $234.56(26.43,437.04)$ & $158.81(-79.39,396.13)$ & $177.55(74.83,317.05)$ & 0.49 \\
\hline \multicolumn{5}{|c|}{ Node-splittings of SBP } \\
\hline ACEI, ARB & $-1.85(-6.79,3.06)$ & $3.78(-12.61,20.69)$ & $-1.50(-6.22,3.18)$ & 0.53 \\
\hline ACEI, CCB & $4.90(-1.19,11.23)$ & $0.42(-16.72,16.41)$ & $4.70(-1.30,9.96)$ & 0.58 \\
\hline $\mathrm{ARB}, \mathrm{CCB}$ & $2.58(-12.98,18.44)$ & $6.87(-1.02,14.93)$ & $6.17(-1.00,12.87)$ & 0.65 \\
\hline \multicolumn{5}{|c|}{ Node-splittings of DBP } \\
\hline ACEI, ARB & $-0.91(-6.63,5.25)$ & $4.05(-17.77,25.81)$ & $-0.69(-5.80,4.95)$ & 0.66 \\
\hline ACEI, CCB & $3.05(-4.94,10.92)$ & $-1.39(-23.74,18.97)$ & $2.81(-4.74,9.45)$ & 0.67 \\
\hline $\mathrm{ARB}, \mathrm{CCB}$ & $-0.15(-22.20,20.92)$ & $3.78(-6.36,13.51)$ & $3.44(-5.65,11.26)$ & 0.73 \\
\hline
\end{tabular}

size of included studies was scant. Therefore, conclusions of eGFR and secondary outcomes were uncertain. Secondly, most of the ADPKD patients were prescribed with combination antihypertensive drugs. Our results were influenced inevitably by mixed drug effects. Thirdly, safety endpoints were poorly defined in included studies. Moreover, this study could not assess subgroup analysis by different ADPKD genotypes (PKD1\&PKD2) with different speed of renal progression.

In conclusion, this network meta-analysis is underpowered to detect differences of antihypertensive treatments on kidney progression in ADPKD patients. More RCTs and research about T-/N- type CCBs will be needed in the future. Use of ARB in clinical practice may be an optimal choice.

\section{MATERIALS AND METHODS}

\section{Search strategy and selection criteria}

We (X.C. and D.B.) searched PubMed, Embase, Ovid, and Cochrane Collaboration (published up to May, 2015) with the following terms: "angiotensin converting enzyme inhibitors", "ACEIs", "ACE inhibitors", "angiotensin receptor blockers", "ARBs", angiotensin receptor antagonists", "beta-blockers", " $\beta$-blockers", "beta-receptor antagonist", "beta adrenergic antagonists", "calcium antagonists", "CCBs", "calcium channel blockers", "diuretics", and the names of specific medications. The references of relevant reviews and clinical studies were checked in case of missed articles. We also searched the Google Scholar and clinical trials website. 


\section{Inclusion and Exclusion Criteria}

Included studies had to meet the following criteria: (1) studies in patients with the diagnosis of ADPKD; (2) antihypertensive drugs were used; (3) RCTs; (4) adults. Studies with the following criteria were excluded: (1) ADPKD patients with end stage renal disease or dialysis; (2) cohort studies or case-control studies.

\section{Data Extraction and methodological quality assessment}

Two authors (X.C. and Z.C.) independently checked the included studies to extract the relevant data and assess study bias/risk. Discrepancy was settled by discussion. We evaluated the bias/risk of the included trials by using the Cochrane Risk of Bias Scale [25]. The primary outcome was estimated glomerular filtration rate (eGFR, $\mathrm{mL} / \mathrm{min}$ or $\left.\mathrm{mL} / \mathrm{min} / 1.73 \mathrm{~m}^{2}\right)$. Secondary outcomes were serum creatinine $(\mathrm{Scr}, \mathrm{mg} / \mathrm{dL}$ ), urinary albumin excretion (UAE, $\mathrm{mg} / \mathrm{d}$ or $\mathrm{mg} / \mathrm{g}$ ), systolic blood pressure (SBP, $\mathrm{mm} \mathrm{Hg}$ ), diastolic blood pressure (DBP, $\mathrm{mm} \mathrm{Hg}$ ), mean artery pressure (MAP, mm $\mathrm{Hg}$ ), left ventricular mass index (LVMI, $\mathrm{g} / \mathrm{m}^{2}$ ).

\section{Statistical analysis}

The meta-analysis was carried out according with the PRISMA extension statement for reporting of systematic review and network meta-analysis [26]. Heterogeneity was measured through Q test and $I^{2}$ statistics [27]. $I^{2}<25 \%$ was considered as low and $I^{2}>75 \%$ as high. We estimated the mean difference (MD) with $95 \%$ confidence interval (CI) for the continuous calculations in the random effects model. Sensitivity analysis was estimated by the influence analysis which excluded each study to check the stability.

Network meta-analysis was performed by a Bayesian Markov Chain Morte Carlo method. Network meta-analysis needs to assume transitivity which holds when all direct comparisons between drugs have similar distribution of effect modifiers. The effect modifiers in this study included the BP at baseline, the level of eGFR, UAE, Scr and LVMI. All indirect treatment comparisons were taken together to get an integrated estimate of the included treatments. Different outcomes between direct and indirect evidences suggested that the assumption of transitivity might not depend. Included trials were grouped into six comparison categories: ACEI, ARB, ACEI+ARB, $\beta$-blocker, dilazep and CCB. Evaluation of inconsistency used the node-splitting. Network meta-analysis was calculated in both consistency and inconsistency models. Ranking of the drugs in each outcome was measured by Bayesian probability analysis. Software used were WinBUGS version 1.4 (Imperial College and Medical
Research Council, London), Revman 5.4 (Cochrane group) and Stata version 13.1 (Stata Corp., College Station, Texas) [28].

\section{ACKNOWLEDGMENTS}

This study was supported by China Postdoctoral Science Foundation funded project, and National Natural Science Foundation of China (30900692, 81370844).

\section{FUNDINGS}

This study was supported by China Postdoctoral Science Foundation funded project, and National Natural Science Foundation of China (30900692, 81370844).

\section{CONFLICTS OF INTEREST}

All the authors have no conflict of interest. The results presented in this paper have not been published previously.

\section{REFERENCES}

1. Torres VE, Abebe KZ, Chapman AB, Schrier RW, Braun WE, Steinman TI, Winklhofer FT, Brosnahan G, Czarnecki PG, Hogan MC, Miskulin DC, Rahbari-Oskoui FF, Grantham JJ, et al. Angiotensin blockade in late autosomal dominant polycystic kidney disease. N Engl J Med. 2014; 371: 2267-2276.

2. Schrier RW, Abebe KZ, Perrone RD, Torres VE, Braun WE, Steinman TI, Winklhofer FT, Brosnahan G, Czarnecki PG, Hogan MC, Miskulin DC, Rahbari-Oskoui FF, Grantham JJ, et al. Blood pressure in early autosomal dominant polycystic kidney disease. N Engl J Med. 2014; 371: 2255-2266.

3. Nutahara K, Higashihara E, Horie S, Kamura K, Tsuchiya K, Mochizuki T, Hosoya T, Nakayama T, Yamamoto N, Higaki Y, Shimizu T. Calcium channel blocker versus angiotensin II receptor blocker in autosomal dominant polycystic kidney disease. Nephron Clin Pract. 2005; 99: c18-23.

4. Zeltner R, Poliak R, Stiasny B, Schmieder RE, Schulze BD. Renal and cardiac effects of antihypertensive treatment with ramipril vs metoprolol in autosomal dominant polycystic kidney disease. Nephrol Dial Transplant. 2008; 23: 573579 .

5. Ecder T, Edelstein CL, Fick-Brosnahan GM, Johnson AM, Chapman AB, Gabow PA, Schrier RW. Diuretics versus angiotensin-converting enzyme inhibitors in autosomal dominant polycystic kidney disease. Am J Nephrol. 2001; 21: 98-103.

6. van Dijk MA, Breuning MH, Duiser $\mathrm{R}$, van Es LA, Westendorp RG. No effect of enalapril on progression in autosomal dominant polycystic kidney disease. Nephrol 
Dial Transplant. 2003; 18: 2314-2320.

7. Kanno Y, Suzuki H, Okada H, Takenaka T, Saruta T. Calcium channel blockers versus ACE inhibitors as antihypertensives in polycystic kidney disease. QJM. 1996; 89: 65-70.

8. Ecder T, Chapman AB, Brosnahan GM, Edelstein CL, Johnson AM, Schrier RW. Effect of antihypertensive therapy on renal function and urinary albumin excretion in hypertensive patients with autosomal dominant polycystic kidney disease. Am J Kidney Dis. 2000; 35: 427-432.

9. Palmer SC, Mavridis D, Navarese E, Craig JC, Tonelli M, Salanti G, Wiebe N, Ruospo M, Wheeler DC, Strippoli GF. Comparative efficacy and safety of blood pressure-lowering agents in adults with diabetes and kidney disease: a network meta-analysis. Lancet. 2015; 385: 2047-2056.

10. Schrier R, McFann K, Johnson A, Chapman A, Edelstein C, Brosnahan G, Ecder T, Tison L. Cardiac and renal effects of standard versus rigorous blood pressure control in autosomal-dominant polycystic kidney disease: results of a seven-year prospective randomized study. J Am Soc Nephrol. 2002; 13: 1733-1739.

11. Cadnapaphornchai MA, McFann K, Strain JD, Masoumi A, Schrier RW. Prospective change in renal volume and function in children with ADPKD. Clin J Am Soc Nephrol. 2009; 4: 820-829.

12. Ulusoy S, Ozkan G, Orem C, Kaynar K, Kosucu P, Kiris A. A comparison of the effects of ramipril and losartan on blood pressure control and left ventricle hypertrophy in patients with autosomal dominant polycystic kidney disease. Ren Fail. 2010; 32: 913-917.

13. Nakamura T, Sato E, Fujiwara N, Kawagoe Y, Yamada S, Ueda Y, Koide H. Changes in urinary albumin excretion, inflammatory and oxidative stress markers in ADPKD patients with hypertension. Am J Med Sci. 2012; 343: 4651.

14. Ulusoy S, Ozkan G, Kosucu P, Kaynar K, Eyuboglu I. A comparison of the effects of losartan and ramipril on blood pressure, renal volume and progression in polycystic kidney disease: A 5-Year follow-up. Hippokratia. 2012; 16: 143148.

15. Nakamura T, Ushiyama C, Takahashi $Y$, Tanaka A, Shimada N, Ebihara I, Koide H. Effect of dilazep dihydrochloride on urinary albumin excretion in patients with autosomal dominant polycystic kidney disease. Nephron. 2001; 88: 80-82.

16. Patch C, Charlton J, Roderick PJ, Gulliford MC. Use of antihypertensive medications and mortality of patients with autosomal dominant polycystic kidney disease: a population-based study. Am J Kidney Dis. 2011; 57: 856862.

17. Maschio G, Alberti D, Janin G, Locatelli F, Mann JF, Motolese M, Ponticelli C, Ritz E, Zucchelli P. Effect of the angiotensin-converting-enzyme inhibitor benazepril on the progression of chronic renal insufficiency. The
Angiotensin-Converting-Enzyme Inhibition in Progressive Renal Insufficiency Study Group. N Engl J Med. 1996; 334 : 939-945.

18. Chapman AB, Gabow PA, Schrier RW. Reversible renal failure associated with angiotensin-converting enzyme inhibitors in polycystic kidney disease. Ann Intern Med. 1991; 115: 769-773.

19. Schrier RW, Brosnahan G, Cadnapaphornchai MA, Chonchol M, Friend K, Gitomer B, Rossetti S. Predictors of autosomal dominant polycystic kidney disease progression. J Am Soc Nephrol. 2014; 25: 2399-2418.

20. Chapman AB. Approaches to testing new treatments in autosomal dominant polycystic kidney disease: insights from the CRISP and HALT-PKD studies. Clin J Am Soc Nephrol. 2008; 3: 1197-1204.

21. Ruggenenti P, Perna A, Gherardi G, Benini R, Remuzzi G. Chronic proteinuric nephropathies: outcomes and response to treatment in a prospective cohort of 352 patients with different patterns of renal injury. Am J Kidney Dis. 2000; 35: 1155-1165.

22. Mitobe M, Yoshida T, Sugiura H, Shiohira S, Shimada K, Nitta K, Tsuchiya K. Clinical effects of calcium channel blockers and renin-angiotensin-aldosterone system inhibitors on changes in the estimated glomerular filtration rate in patients with polycystic kidney disease. Clin Exp Nephrol. 2010; 14: 573-577.

23. Yamaguchi T, Nagao S, Wallace DP, Belibi FA, Cowley BD, Pelling JC, Grantham JJ. Cyclic AMP activates B-Raf and ERK in cyst epithelial cells from autosomal-dominant polycystic kidneys. Kidney Int. 2003; 63: 1983-1994.

24. Ikeda M, Guggino WB. Do polycystins function as cation channels? Curr Opin Nephrol Hypertens. 2002; 11: 539545 .

25. Higgins JP, Altman DG, Gotzsche PC, Juni P, Moher D, Oxman AD, Savovic J, Schulz KF, Weeks L, Sterne JA. The Cochrane Collaboration's tool for assessing risk of bias in randomised trials. BMJ. 2011; 343: d5928.

26. Hutton B, Salanti G, Caldwell DM, Chaimani A, Schmid $\mathrm{CH}$, Cameron C, Ioannidis JP, Straus S, Thorlund K, Jansen JP, Mulrow C, Catala-Lopez F, Gotzsche PC, et al. The PRISMA Extension Statement for Reporting of Systematic Reviews Incorporating Network Meta-analyses of Health Care Interventions: Checklist and Explanations. Ann Intern Med. 2015; 162: 777-784.

27. Higgins JP, Thompson SG, Deeks JJ, Altman DG. Measuring inconsistency in meta-analyses. BMJ. 2003; 327 : 557-560.

28. Chaimani A, Higgins JP, Mavridis D, Spyridonos P, Salanti G. Graphical tools for network meta-analysis in STATA. PLoS One. 2013; 8: e76654. 